\title{
PERFIL DOS ESTUDANTES PÚBLICO-ALVO DA EDUCAÇÃO ESPECIAL NA EDUCAÇÃO SUPERIOR BRASILEIRA ANTES DA LEI DE RESERVA DE VAGAS
}

\author{
PROFILE OF SPECIAL EDUCATION TARGET STUDENTS IN HIGHER EDUCATION \\ IN BRAZIL BEFORE THE LAW OF RESERVATION OF VACANCIES
}

\section{PERFIL DEL ALUMNADO QUE DEMANDA DE LA EDUCACIÓN ESPECIAL EN LA EDUCACIÓN SUPERIOR EN BRASIL ANTES DE LA LEY DE RESERVA DE VACANTES}

\author{
Luiz Renato Martins da Rocha ${ }^{1}$ 0000-0002-2884-4956 \\ Cristina Broglia Feitosa de Lacerda ${ }^{2}$ 0000-0002-3250-1374 \\ Elisângela Aparecida da Silva Lizzi ${ }^{3}$ 0000-0001-7064-263X
}

1 Universidade Tecnológica Federal do Paraná - Cornélio Procópio, Paraná, Brasil; luizrenatomr@gmail.com

${ }^{2}$ Universidade Federal de São Carlos - São Carlos, São Paulo; cbflacerda@ gmail.com

3 Universidade Tecnológica Federal do Paraná - Cornélio Procópio, Paraná, Brasil; elisangelalizzi@utfpr.edu.br

\section{RESUMO}

O objetivo principal da presente pesquisa é mapear e analisar aspectos relativos aos estudantes público-alvo da Educação Especial (PAEE), sobretudo traçando um perfil destes no ano de 2015. Os estudantes PAEE na Educação Superior brasileira representavam, em 2015, 0,47\% em comparação as matrículas no geral nos cursos de graduação (INEP, 2015). A pesquisa foi quantitativa, com método descritivo e exploratório. A lei de reserva de vagas alterada em 2016 (Lei $n^{\circ} 13.409$ ) para contemplar as pessoas com deficiência passa a ter um papel fundamental na democratização do ingresso desses estudantes na Educação Superior. Por meio da análise dos dados, foi possível descrever o PAEE na Educação Superior brasileira, entender quantos e quem são, sobretudo no tocante a raça/cor e idade. Com os dados obtidos na análise realizada, foi possível identificar gargalos e propor a construção de políticas públicas mais efetivas e direcionadas a esse público, por vezes alijado da educação.

Palavras chave: educação especial; educação superior; matrículas; perfil.

\begin{abstract}
The main objective of this research is to map and analyze aspects related to target students in Higher Education, by drawing their profile in 2015. In 2015, the students PAEE in Brazilian Higher Education represented $0.47 \%$ of enrollments in general undergraduate courses (INEP, 2015). The vacancy reservation law amended in 2016 ( Law n $^{\circ} 13.409$ ) to include people with disabilities now plays a fundamental role in democratizing the admission of these students. The research was quantitative, with a descriptive and exploratory method. Through data analysis, it was possible to describe the special education target students in Brazilian Higher Education, to understand how many and who they are, with regard to race/color and age and. With these data, it was possible to identify bottlenecks and propose the construction of more effective public policies for this public, sometimes kept from education.
\end{abstract}

Keywords: special education; higher education; enrollment; profile. 


\section{RESUMEN}

El objetivo principal de la presente investigación es mapear y analizar aspectos relacionados con alumnado que demanda de la educación especial (PAEE en portugués), sobre todo, delinear su perfil en el año 2015. El alumnado PAEE en la educación superior brasileira representaba, en 2015, el 0,47\% de la matrícula de los cursos de graduación (INEP, 2015). La Ley de reserva de vacantes, modificada en 2016 (Ley $\mathrm{n}^{\circ}$ 13.409) para contemplar a las personas con discapacidad pasa a tener un rol fundamental en la democratización del ingreso de este alumnado. La investigación fue cuantitativa, con método descriptivo y exploratorio. Mediante el análisis de los datos fue posible describir el PAEE en la educación superior brasileira, para comprender cuántos y quiénes son, con respecto a raza/color y edad. Con estos datos, fue posible identificar cuellos de botella y elaborar propuestas para la construcción de políticas públicas más efectivas para esta población, a veces ignoradas en la educación.

Palabras clave: educación especial; educación superior; matrículas; perfil.

\section{Introdução}

A educação superior ${ }^{\mathrm{i}}$ brasileira tem se expandido nos últimos anos de forma exponencial e os reflexos desse crescimento têm sido o aumento da população universitária, bem como daqueles que são público-alvo da educação especial ${ }^{\mathrm{ii}}$ (PAEE), principalmente e sobretudo após a publicação da lei nº 13.409, de dezembro de 2016 (BRASIL, 2016), que obriga as instituições federais de educação superior (IFES) a realizar a reserva de vagas para pessoas com deficiência.

Outrora, esse nível de ensino era restrito a uma elite: "Historicamente acessível para os estratos sociais mais privilegiados, as universidades e faculdades pelo país têm se tornado progressivamente mais abertas para camadas sociais que até então pouco usufruíam o direito à educação em nível superior” (SENKEVICSI; MELLO, 2019, p. 186). Segundo Durham (2003), a preocupação da aristocracia (ainda nos séculos XVIII e XIX) estava voltada à formação de profissionais necessários para gerir o Estado, e os que alcançavam esse nível de ensino eram aqueles pertencentes às famílias mais privilegiadas e, consequentemente, os que tinham os melhores postos de trabalho, quando diplomados.

As instituições de educação superior (IES), pensadas inicialmente para serem homogêneas, começam a sofrer transformações graduais, com a introdução de políticas públicas mais atentas à diversidade. Nesse contexto, a lei nº 13.409/2016 (BRASIL, 2016) vem alterar a lei $\mathrm{n}^{\mathrm{o}}$ 12.711/2012 (BRASIL, 2012), que reservava vagas nas IFES, bem como nas instituições federais de ensino técnico de nível médio, para pessoas autodeclaradas pretas, pardas e indígenas, ampliando o público contemplado e incluindo também as pessoas com deficiência um segmento da população antes alijado por políticas pouco sensíveis às suas singularidades. 
Por esse motivo, essa lei “[...] pode ser considerada potencialmente importante como estratégia para reduzir a estratificação social no acesso à educação" (SENKEVICSI; MELLO, 2019, p. 189).

Cantorani et al. (2020) realizam ampla busca em bases indexadoras (SciELO e Web of Science) sobre a temática da acessibilidade e inclusão de pessoas com deficiência na educação superior, que, segundo os pesquisadores, tem se constituído objeto de pesquisa no meio acadêmico; no entanto, ainda incipientes são as publicações: identificaram um total de 45 artigos, que, analisados, permitiram concluir que:

[...] apenas três estudos foram direcionados a políticas públicas de acesso ao ensino superior para PcDs siii. Estes, contudo, não abordam a lei n. 13.409/2016, a qual é recente e responsável por alterar significativamente a forma como as IFES passam a disponibilizar suas reservas de vagas direcionadas a essa população (p. 5).

As IFES estão em processo de mudanças, a fim de atender estudantes com deficiência, com isso, a acessibilidade e a inclusão têm se tornado pauta cada vez mais eminente nas discussões realizadas pela gestão das instituições, sobretudo após a promulgação da lei 13.409/2016. No entanto, "O que deve ser discutido, de forma ampla, é a necessidade de geração de condições para a sua efetivação por parte do governo federal" (CANTORANI et al., 2020, p. 18), ou seja, as normas legais brasileiras voltadas à inclusão da pessoa com deficiência restringem-se, majoritariamente, à possibilidade de ingresso dos estudantes com deficiência, mas não , na mesma proporção, à sua permanência, uma vez que "[...] as dificuldades para as IFES são ainda maiores após o processo seletivo, pois não receberam o aporte financeiro e de pessoal, necessário e urgente, para adequarem-se às novas obrigações" (CANTORANI et al., 2020, p. 13).

Para atender às finalidades deste artigo, nos interessam ainda informações presentes nos dados censitários. Os censos/contagens podem envolver toda a população de um país, como o censo demográfico realizado a cada 10 anos no Brasil. No entanto, existem censos menores, que contabilizam informações de um determinado segmento, como os censos educacionais, que também oferecem informações importantes para o escopo deste estudo. No Brasil, há dois grandes censos educacionais: o censo escolar (da educação básica) e o censo da educação superior.

Assim, nos valeremos, neste artigo, dos dados coletados anualmente no censo da educação superior brasileira e, em algumas vezes, dos dados do censo demográfico de 2010, a fim de caracterizar os estudantes PAEE no ano de 2015, objetivando traçar um perfil que pode 
nos ajudar a melhor compreender sua realidade no tocante ao ingresso nas IES. Pretende-se, com isso, mostrar um retrato desse público antes da lei de reserva de vagas e nos cinco anos da vigência da referida lei, realizando um comparativo, verificando as possíveis evoluções ou involuções dos impactos da legislação na tentativa da composição de um quadro cada vez mais heterogêneo entre os estudantes nas IFES.

Apesar de a lei 13.409/2016 tratar especificamente das instituições federais, outras IES começam a adotar condutas pautadas nessa norma, como forma de garantir maior acesso a esses públicos. Buscamos traçar um panorama de todo o conjunto de IES do país e não apenas de um segmento, pois entendemos que algumas são impactadas de forma direta por ela e, outras, de forma mais indireta.

Ademais, a referida pesquisa descreve e aponta dados que podem subsidiar outras investigações de cunho empírico, trazendo luz a questões pouco discutidas sobre a lei de reserva de vagas e seus impactos nas IES (ROCHA, 2019; CANTORANI et al., 2020; SENKEVICSI; MELLO, 2019).

Com isso, esperamos que este estudo sirva de insumo para o monitoramento e a avaliação da lei ${ }^{\circ}$ 13.409/2016, que tem abrangência nacional. Seus impactos têm que ser conhecidos para que cada uma das IES possa entender a importância que uma lei dessa envergadura tem para a composição da heterogeneidade de seus estudantes e a relevância das modificações quando estes chegam às IES e passam a reivindicar seu espaço de direito.

\section{Caminhos percorridos na seleção e análise dos dados}

A pesquisa em tela utiliza abordagem quantitativa de base populacional, descritiva e exploratória. O PAEE registrado no Censo da Educação Superior no ano de 2015 (BRASIL, 2015) constituiu um total de 37.297 estudantes com cegueira, baixa visão, surdez, deficiência auditiva, deficiência física, surdocegueira, deficiência múltipla, deficiência intelectual, autismo, Síndrome de Asperger, Síndrome de Rett, transtorno desintegrativo da infância e altas habilidades/superdotação, inserido no montante de 8.027.297 estudantes matriculados. Todos

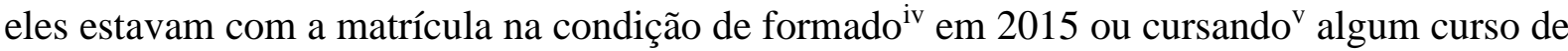
graduação presencial ou a distância, da rede privada ou pública, fazendo parte das análises realizadas na presente pesquisa.

A abertura dos microdados da Educação Superior de 2015 ocorreu por meio do software estatístico SAS ® (Versão 9.2) (Statistical Analysis Software), o qual nos possibilitou a investigação de um grande volume de informações acerca do conjunto de estudantes 
brasileiros das IES. Para isso, foi utilizado um computador de alto desempenho para a obtenção e análise dos dados e uma impressora multifuncional (para melhor visualizar os dados de forma impressa). Além disso, usaram-se o software R (versão 3.5) e o Microsoft® Office Excel.

Para a abertura e seleção dos dados, aplicamos, primeiramente, o filtro pelo qual excluímos os estudantes matriculados em cursos sequenciais ${ }^{\mathrm{vi}}$, permanecendo apenas aqueles matriculados em cursos de graduação ${ }^{\text {vii }}$, haja vista o objetivo da presente pesquisar estar voltado especificamente para a educação superior. Após esse filtro, excluíram-se os alunos desvinculados do curso $^{\text {viii }}$, falecidos ${ }^{\mathrm{ix}}$, com matrícula trancada ${ }^{\mathrm{x}}$ e transferidos para outro curso da mesma IES ${ }^{x i}$.

O segundo filtro ${ }^{\text {xii }}$ empregado foi para a seleção dos alunos com deficiência, transtornos globais do desenvolvimento ou altas habilidades/superdotação, num total de 37.927 matrículas. Nesse caso, o filtro foi: "IN_ALUNO_DEF_TGD_SUPER $=0$ ", $=0$ significando que ele não tem deficiência; $=1$, que ele tem deficiência, e =2, que a IES não dispõe dessa informação. Tal seleção está mais bem descrita no fluxograma a seguir.

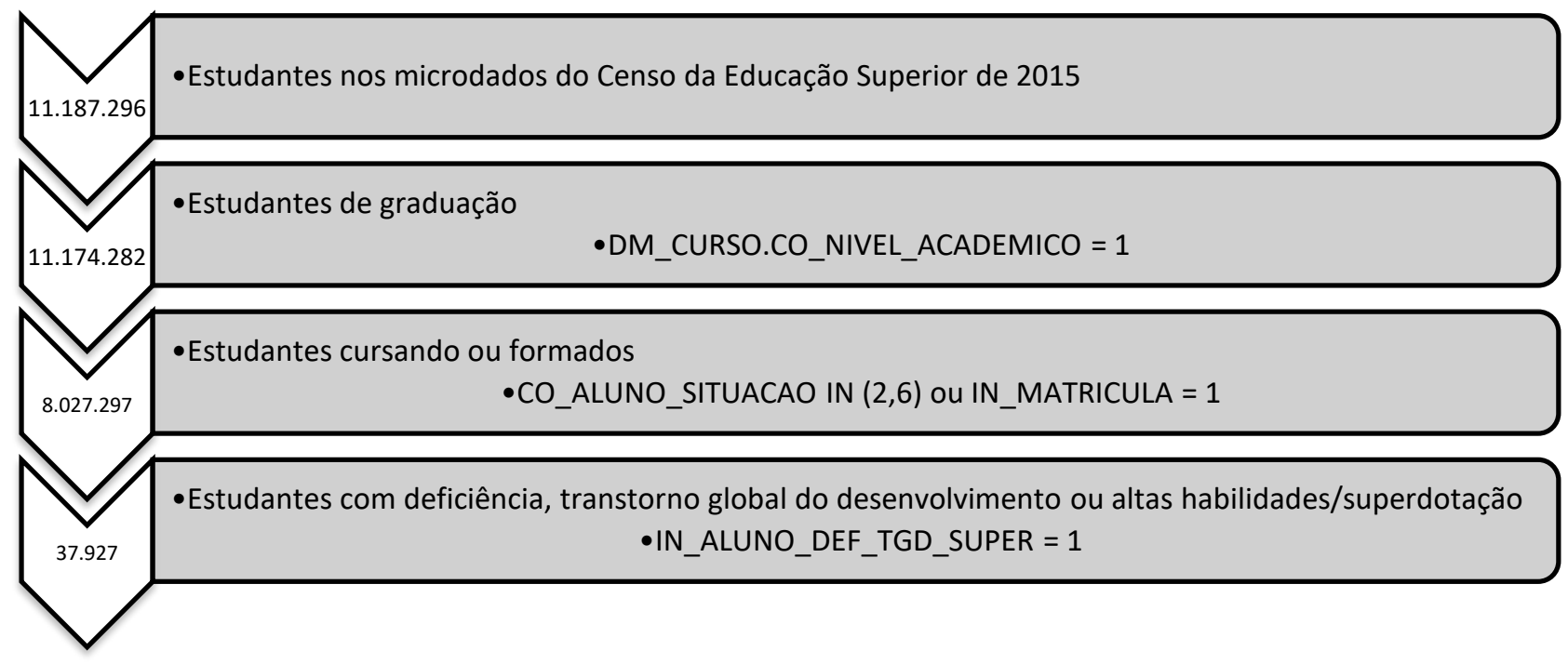

Figura 1 - Fluxograma na seleção dos filtros empregados

Vale ressaltar que os dados disponibilizados pelo Instituto Nacional de Estudos e Pesquisas Educacionais Anísio Teixeira - INEP, no Censo da Educação Superior são coletados anualmente e são inseridos no site do censo por um pesquisador institucional (PI), indicado pela instituição de educação superior (IES). Cada IES coleta os dados a serem informados de diferentes formas, em diferentes momentos ao longo do ano letivo, e os dados relativos ao perfil do estudante são obtidos por meio de autodeclaração (BRASIL, 2015).

Esta pesquisa não lida diretamente com seres humanos, mas com dados estatísticos provenientes do Inep e, de acordo com as Diretrizes e Normas Regulamentadoras de Pesquisa 
Envolvendo Seres Humanos e Complementares (Resolução nº 466/2012 do Conselho Nacional de Saúde), está dispensada de aprovação desse comitê.

Devido ao grande volume de informações analisadas para esta pesquisa, necessitou-se de ferramentas não triviais para sistematização dos resultados, que demandou conhecimentos sobre programação e métodos estatísticos aplicados. Desse modo, sumarizamos os dados em tabelas e gráficos, para uma melhor visualização desses números, separando-os por regiões brasileiras.

Nas tabelas, tem-se primeiro o valor geral daquele público naquela categoria; na segunda linha a soma de $100 \%$ na coluna, ou seja, apresenta informações concernentes ao representativo da região em relação às matrículas no geral; na terceira linha, corresponde à soma de $100 \%$ na linha, mostrando informações sobre a região e a sua correspondência em relação às suas próprias matrículas. Dessa forma, estruturadas as planilhas, conseguimos identificar quanto aquele percentual representa no Brasil em relação ao total de matrículas (coluna) e quanto representa uma determinada variável, em uma determinada região (linha), conforme a figura 2.

\begin{tabular}{|c|c|c|c|c|c|c|c|c|c|c|c|}
\hline \multirow[t]{2}{*}{$\begin{array}{l}\text { Siglas dos } \\
\text { Estados }\end{array}$} & \multicolumn{5}{|c|}{ PAEE } & \multicolumn{5}{|c|}{ Geral } & \multirow{2}{*}{$\begin{array}{l}\text { A primeira linha refere-se ao } \\
\text { número de matriculas naquele } \\
\text { determinado eixo (absoluto) }\end{array}$} \\
\hline & Branco & Preto & Pardo & Amar & Indig & Branco & Preto & Pardo & Amar & Indig & \\
\hline & 14.909 & 4.254 & 9.650 & 705 & 289 & 2.903 .256 & 429.632 & 1.743 .002 & 116.036 & 32.147 & A segunda linha refere-se ao \\
\hline Brasil & $\begin{array}{c}100 \% \\
39,31 \%\end{array}$ & $\begin{array}{c}100 \% \\
11,22 \%\end{array}$ & $\begin{array}{c}100 \% \\
25,44 \%\end{array}$ & $\begin{array}{l}100 \% \\
1,86 \%\end{array}$ & $\begin{array}{l}100 \% \\
0,76 \%\end{array}$ & $\begin{array}{c}100 \% \\
36,17 \%\end{array}$ & $\begin{array}{l}100 \% \\
5,35 \%\end{array}$ & $\begin{array}{r}100 \% \\
21,71 \%\end{array}$ & $\begin{array}{l}100 \% \\
1,45 \%\end{array}$ & $\begin{array}{l}100 \% \\
0,4 \%\end{array}$ & $\begin{array}{l}\text { percentual na coluna } \\
\text { A terceira linha refere-se ao } \\
\text { percentual na linha }\end{array}$ \\
\hline
\end{tabular}

Figura 2 - Leitura das tabelas (exemplo)

É possível identificar ainda, na figura 2, que havia na educação superior brasileira, em 2015, um total de 14.909 matrículas de estudantes PAEE de cor branca, o que representa 100\% na coluna. Na linha, esses estudantes representam 39,91\% do total, e os outros 60,69\% são de estudantes PAEE de cor preta, amarela, indígena, parda e aqueles sobre os quais o Censo de 2015 não dispõe de informação ou estudantes que não quiseram declarar-se nesse item.

\section{Perfil dos estudantes PAEE}

Conforme os dados apresentados a seguir, em 2015 havia 37.927 estudantes PAEE na educação superior, de um total de 8.027.297 estudantes no geral, o que representa $0,47 \%$ de estudantes PAEE (BRASIL, 2015), número bastante baixo, se considerarmos que o IBGE contabilizou a população com deficiência (física, auditiva, visual e mental/intelectual) no Brasil em torno de 8,3\% (IBGE, 2010). 
Tabela 1 - Número de matrículas de estudantes PAEE e matrículas no geral

\begin{tabular}{|c|c|c|c|c|c|}
\hline \multirow[b]{2}{*}{$\begin{array}{l}\text { Brasil e } \\
\text { Regiões }\end{array}$} & \multicolumn{3}{|c|}{ PAEE } & \multicolumn{2}{|c|}{ Geral } \\
\hline & Matrículas & $\begin{array}{c}\text { Matrículas } \\
\text { Porcentagem na } \\
\text { coluna/Brasil }\end{array}$ & $\begin{array}{c}\text { Matrículas } \\
\text { Porcentagem } \\
\text { em } \\
\text { comparação as } \\
\text { matrículas no } \\
\text { geral }\end{array}$ & $\begin{array}{l}\text { Matrículas na } \\
\text { Ed. Superior }\end{array}$ & $\begin{array}{l}\text { Matrículas } \\
\text { porcentagem na } \\
\text { coluna/Brasil }\end{array}$ \\
\hline Brasil & 37.927 & $100,00 \%$ & $0,47 \%$ & 8.027 .297 & $100,00 \%$ \\
\hline Norte & 2.949 & $7,78 \%$ & $0,46 \%$ & 647.609 & $8,07 \%$ \\
\hline Nordeste & 11.751 & $30,98 \%$ & $0,69 \%$ & 1.694 .680 & $21,11 \%$ \\
\hline Sudeste & 12.928 & $34,09 \%$ & $0,36 \%$ & 3.618 .711 & $45,08 \%$ \\
\hline Sul & 6.501 & $17,14 \%$ & $0,50 \%$ & 1.311 .201 & $16,33 \%$ \\
\hline Centro-Oeste & 3.798 & $10,01 \%$ & $0,50 \%$ & 755.096 & $9,41 \%$ \\
\hline
\end{tabular}

A região brasileira com maior percentual proporcional de matrículas de estudantes PAEE era a região Nordeste $(0,69 \%)$ e esta, por sua vez, representava $30,98 \%$ das matrículas desse público no Brasil, índice bastante alto, se considerarmos que, nas matrículas no geral, essa mesma região conta com $21,11 \%$ de todas as matrículas na educação superior no Brasil (INEP, 2015). A região Sudeste era a região que tem o menor percentual de estudantes PAEE: 0,36\% e representa 34,09\% das matrículas do PAEE do Brasil, no entanto, contava com mais de $45 \%$ de todas as matrículas no geral, ou seja, com relação ao PAEE, seria esperado um número maior de matrículas (proporcional à sua representatividade no geral), que, entretanto, não se verifica.

Fica visível que: a região Nordeste vinha desenvolvendo um trabalho bastante eficaz na "captura"/ingresso dos estudantes PAEE na educação superior. Quanto à região Sudeste, “[...] apesar do grande quantitativo de pessoas e possibilidades [econômicas] [...] ela tinha percentuais menores de PAEE nas IES [...]” (ROCHA, 2019, p. 143). É preciso uma investigação mais detalhada para se conhecer o que vinha sido realizado no Nordeste que destacava essa região das demais regiões brasileiras. Talvez a proposição de políticas públicas mais setorizadas seja um caminho eficaz, sobretudo, para que se tenha uma participação mais representativa e equilibrada dos estudantes PAEE na educação superior em cada um dos estados e regiões brasileiras.

Segundo pesquisa realizada por Martins, Leite e Lacerda (2015): "De modo geral, o quadro de matrículas de pessoas com deficiência no ensino superior evolui em termos numéricos, mas ainda representa uma camada mínima da população com deficiência 
efetivamente matriculada nessa etapa da escolarização" (p. 1008). Nesse sentido, as referidas autoras endossam o que foi constatado nas estatísticas aqui destacadas, nas quais se verificam baixos percentuais, se comparados às matrículas no geral e à população com deficiência registrada pelo IBGE (2010). Ou seja, há um gargalo entre o percentual de pessoas com deficiência na população e o percentual daqueles que chegam à educação superior brasileira que precisa ser melhor investigado.

Tabela 2 - PAEE: distribuição por características - Brasil - 2015

\begin{tabular}{|c|c|c|c|c|c|c|}
\hline Brasil e Regiões & 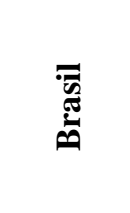 & $\stackrel{0}{\check{c}}$ & $\begin{array}{l}\frac{0}{0} \\
\stackrel{0}{0} \\
z \\
Z\end{array}$ & 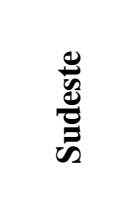 & Б) & 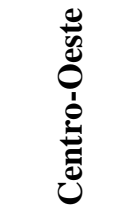 \\
\hline \multirow{3}{*}{ Síndrome de Asperger } & 139 & 5 & 26 & 46 & 41 & 21 \\
\hline & $100 \%$ & $3,6 \%$ & $18,71 \%$ & $33,09 \%$ & $29,5 \%$ & $15,11 \%$ \\
\hline & $0,37 \%$ & $0,17 \%$ & $0,22 \%$ & $0,36 \%$ & $0,63 \%$ & $0,55 \%$ \\
\hline \multirow{3}{*}{$\begin{array}{l}\text { Associação de } \\
\text { características PAEE }\end{array}$} & 618 & 13 & 65 & 203 & 190 & 147 \\
\hline & $100 \%$ & $2,1 \%$ & $10,52 \%$ & $32,85 \%$ & $30,74 \%$ & $23,79 \%$ \\
\hline & $1,63 \%$ & $0,44 \%$ & $0,55 \%$ & $1,57 \%$ & $2,92 \%$ & $3,87 \%$ \\
\hline \multirow{3}{*}{ Deficiência Auditiva } & 5.149 & 815 & 1.298 & 1.744 & 878 & 414 \\
\hline & $100 \%$ & $15,83 \%$ & $25,21 \%$ & $33,87 \%$ & $17,05 \%$ & $8,04 \%$ \\
\hline & $13,58 \%$ & $27,64 \%$ & $11,05 \%$ & $13,49 \%$ & $13,51 \%$ & $10,90 \%$ \\
\hline \multirow{3}{*}{ Autismo } & 155 & 0 & 78 & 35 & 37 & 5 \\
\hline & $100 \%$ & 0 & $50,32 \%$ & $22,58 \%$ & $23,87 \%$ & $3,23 \%$ \\
\hline & $0,41 \%$ & 0 & $0,66 \%$ & $0,27 \%$ & $0,57 \%$ & $0,13 \%$ \\
\hline \multirow{3}{*}{ Baixa Visão } & 8.851 & 617 & 2.394 & 3.075 & 1.678 & 1.087 \\
\hline & $100 \%$ & $6,97 \%$ & $27,05 \%$ & $34,74 \%$ & $18,96 \%$ & $12,28 \%$ \\
\hline & $23,34 \%$ & $20,92 \%$ & $20,37 \%$ & $23,79 \%$ & $25,81 \%$ & $28,62 \%$ \\
\hline \multirow{3}{*}{ Cegueira } & 1.885 & 99 & 582 & 681 & 356 & 167 \\
\hline & $100 \%$ & $5,25 \%$ & $30,88 \%$ & $36,13 \%$ & $18,89 \%$ & $8,86 \%$ \\
\hline & $4,97 \%$ & $3,36 \%$ & $4,95 \%$ & $5,27 \%$ & $5,48 \%$ & $4,40 \%$ \\
\hline Transtorno & 93 & 12 & 9 & 55 & 12 & 5 \\
\hline Desintegrativo da & $100 \%$ & $12,9 \%$ & $9,68 \%$ & $59,14 \%$ & $12,9 \%$ & $5,38 \%$ \\
\hline Infância & $0,25 \%$ & $0,41 \%$ & $0,08 \%$ & $0,43 \%$ & $0,18 \%$ & $0,13 \%$ \\
\hline \multirow{3}{*}{ Deficiência Física } & 12.638 & 1.096 & 2.796 & 5.309 & 2.369 & 1.068 \\
\hline & $100 \%$ & $8,67 \%$ & $22,12 \%$ & $42,01 \%$ & $18,75 \%$ & $8,45 \%$ \\
\hline & $33,32 \%$ & $37,17 \%$ & $23,79 \%$ & $41,07 \%$ & $36,44 \%$ & $28,12 \%$ \\
\hline \multirow{3}{*}{ Deficiência Intelectual } & 1.464 & 42 & 132 & 445 & 220 & 625 \\
\hline & $100 \%$ & $2,87 \%$ & $9,02 \%$ & $30,4 \%$ & $15,03 \%$ & $42,69 \%$ \\
\hline & $3,86 \%$ & $1,42 \%$ & $1,12 \%$ & $3,44 \%$ & $3,38 \%$ & $16,46 \%$ \\
\hline \multirow{3}{*}{ Deficiência Múltipla } & 431 & 52 & 101 & 139 & 104 & 35 \\
\hline & $100 \%$ & $12,06 \%$ & $23,43 \%$ & $32,25 \%$ & $24,13 \%$ & $8,12 \%$ \\
\hline & $1,14 \%$ & $1,76 \%$ & $0,86 \%$ & $1,08 \%$ & $1,60 \%$ & $0,92 \%$ \\
\hline \multirow{3}{*}{ Síndrome de Rett } & 19 & 5 & 4 & 8 & 1 & 1 \\
\hline & $100 \%$ & $26,32 \%$ & $21,05 \%$ & $42,11 \%$ & $5,26 \%$ & $5,26 \%$ \\
\hline & $0,05 \%$ & $0,17 \%$ & $0,03 \%$ & $0,06 \%$ & $0,02 \%$ & $0,03 \%$ \\
\hline \multirow{3}{*}{$\begin{array}{l}\text { Altas Habilidades/ } \\
\text { Superdotação }\end{array}$} & 4.774 & 87 & 3.993 & 408 & 209 & 77 \\
\hline & $100 \%$ & $1,82 \%$ & $83,64 \%$ & $8,55 \%$ & $4,38 \%$ & $1,61 \%$ \\
\hline & $12,59 \%$ & $2,95 \%$ & $33,98 \%$ & $3,16 \%$ & $3,21 \%$ & $2,03 \%$ \\
\hline Surdez & $\begin{array}{l}1.619 \\
100 \%\end{array}$ & $\begin{array}{c}82 \\
5,06 \%\end{array}$ & $\begin{array}{c}255 \\
15,75 \%\end{array}$ & $\begin{array}{c}759 \\
46,88 \%\end{array}$ & $\begin{array}{c}380 \\
23,47 \%\end{array}$ & $\begin{array}{c}143 \\
8,83 \%\end{array}$ \\
\hline
\end{tabular}




$\begin{array}{llllll}4,27 \% & 2,78 \% & 2,17 \% & 5,87 \% & 5,85 \% & 3,77 \%\end{array}$

$\begin{array}{ccccccc} & 92 & 24 & 18 & 21 & 26 & 3 \\ \text { Surdocegueira } & 100 \% & 26,09 \% & 19,57 \% & 22,83 \% & 28,26 \% & 3,26 \% \\ & 0,24 \% & 0,81 \% & 0,15 \% & 0,16 \% & 0,40 \% & 0,08 \%\end{array}$

Fonte: Elaborada pelos autores com dados do Inep (2015).

No glossário de termos do módulo do aluno de 2015 (INEP, 2015), disponível no site do Inep, juntamente com a apresentação dos dados, é possível identificar o conceito de cada uma das características que envolvem o PAEE. A síndrome de Asperger é descrita como um:

[...] prejuízo persistente na interação social; desenvolvimento de padrões restritos e repetitivos de comportamento, interesses e atividades; tem início mais tardio do que o autismo ou é percebido mais tarde (entre 3 e 5 anos); atrasos motores ou falta de destreza motora podem ser percebidos antes dos 6 anos; diferentemente do autismo, podem não existir atrasos clinicamente significativos no desenvolvimento cognitivo, na linguagem, nas habilidades de autoajuda apropriadas à idade, no comportamento adaptativo, à exceção da interação social, e na curiosidade pelo ambiente na infância (INEP, 2015, p. 41).

Entre os estudantes PAEE, aqueles com Síndrome de Asperger representavam 0,37\% das matrículas (para o PAEE). A região com o maior percentual era a Sul $(0,63 \%)$ e o menor percentual era registrado no Norte $(0,17 \%)$, diferença de mais de três vezes.

O baixo percentual de estudantes com Síndrome de Asperger chama a atenção para um problema na identificação do PAEE, que pode estar relacionado a dificuldades com o diagnóstico clínico desses sujeitos. Rocha (2019) esclarece que: “[...] é possível que pessoas com essas características não sejam diagnosticadas e estejam presentes na Educação Superior" (p. 166), de forma invisível. Ressalta-se ainda que a subnotificação desse público pode estar presente em outros estudantes PAEE (deficiência intelectual, altas habilidades/superdotação, síndromes e outras).

É possível que a publicação da lei 13.146/2015 (BRASIL, 2015) - que, em seu artigo $2^{\circ}$, discorre sobre o modelo de avaliação biopsicossocial da deficiência, a ser realizado por equipe multiprofissional e interdisciplinar - favoreça, nos próximos anos, a identificação desse público, uma vez que já chegariam na educação superior identificados segundo o Índice de Funcionalidade Brasileiro (IFBr). Na atualidade, na maioria das vezes, o diagnóstico é apoiado no Código Internacional de Doença (CID), que apenas avalia a deficiência sob o ponto de vista clínico (modelo clínico da deficiência), de forma imprecisa e pouco funcional no que tange às expectativas educacionais.

Vale ressaltar que as informações fornecidas ao Censo da Educação Superior, são autodeclaradas. Assim, em tese, não é necessário laudo para incluir uma pessoa como PAEE, 
no entanto, quando o sujeito nem ao menos sabe o que tem, por falta de um diagnóstico, ele não irá se declarar e, portanto, haverá uma subnotificação dos dados. Por essa razão, saúde e educação são importantes aliadas.

A deficiência auditiva é caracterizada no glossário do aluno como: “[...] perda bilateral, parcial ou total, de $41 \mathrm{~dB}$ ou mais, aferida por audiograma nas frequências de $500 \mathrm{~Hz}, 1.000$ Hz, 2.000 Hz e 3.000 Hz" (INEP, 2015, p. 42). No Brasil, esses alunos representavam 13,58\% das matrículas na educação superior. A região Norte $(27,64 \%)$ era a que mais tinha, percentualmente, esses alunos, e o menor percentual estava na região Centro-Oeste $(10,9 \%)$. Estudantes com deficiência auditiva geralmente realizam leitura orofacial e estabelecem comunicação via língua portuguesa, mesmo que precariamente (MEC, 2013, p. 22), o que pode gerar na instituição certo "conforto" ao não ter que fazer grandes adequações para recebê-los. Tal fato poderia explicar a grande variação entre as regiões no tocante à presença da deficiência auditiva e outros públicos da educação especial nos quais as barreiras são "facilmente" transpostas, com poucas alterações na práxis docente ou na estrutura institucional da IES. Assim, por vezes, os estudantes se sentem "desobrigados" a se declarar, e, para a IES, não há motivos para indagar ou providenciar recursos, se eximindo de tal responsabilidade.

O autismo é caracterizado no glossário do aluno como um

[...] prejuízo no desenvolvimento da interação social e da comunicação; pode haver atraso ou ausência do desenvolvimento da linguagem; naqueles que a possuem, pode haver uso estereotipado e repetitivo ou uma linguagem idiossincrática; repertório restrito de interesses e atividades; interesse por rotinas e rituais não funcionais. Manifesta-se antes dos 3 anos de idade. Prejuízo no funcionamento ou atraso em pelo menos uma das três áreas: interação social; linguagem para a comunicação social; jogos simbólicos ou imaginativos (INEP, 2015, p. 42).

Nas IES brasileiras, tínhamos em 2015155 estudantes autistas, o que representava 0,41\% das matrículas dos estudantes PAEE, sendo que, na região Norte, não havia nenhum estudante com essa característica, e o Nordeste era a região com o maior percentual desse público $(0,66 \%)$, bem como era nessa região que cerca de $50 \%$ dos estudantes com autismo da educação superior brasileira estavam. Vale ressaltar que, em 2015, no Censo da Educação superior, "[...] ainda se contam estudantes com autismo, transtorno desintegrativo da infância e Síndrome de Asperger, o que está indo de encontro ao preconizado pelo Manual Diagnóstico e Estatístico de Transtornos Mentais, 5a edição (DSM-V)” (ROCHA, 2019, p. 209). Acreditamos que a versão 2019 será atualizada para constar, ao invés de todas essas categorias, o Transtorno do Espectro Autista (TEA), que engloba todas as características supracitadas. apesar de o DSM ser de 2013, até o Censo de Educação Superior de 2019, não haviam ocorrido 
tais mudanças; já no Censo da Educação Básica, a partir da publicação dos dados de 2019, a modificação de tais características já foi contemplada e o Censo já está em consonância ao DSM V. Vale ainda ressaltar a necessidade para um passo além ao preconizado no DSM V, que é a avaliação de forma biopsicossocial e não mais pelo aspecto meramente quantitativo da deficiência.

A baixa-visão é caracterizada como a "acuidade visual entre 0,3 e 0,05 no melhor olho, com a melhor correção óptica; os casos nos quais a somatória da medida do campo visual em ambos os olhos for igual ou menor que $60^{\circ}$; ou a ocorrência simultânea de quaisquer das condições anteriores" (INEP, 2015, p. 42). Havia um número relativamente grande desse público na educação superior; estes representavam 23, 24\% das matrículas do PAEE e as variações desses alunos eram relativamente pequenas, uma vez que a região com o menor percentual era a Norte $(20,92 \%)$ e a mais representativa, a Centro-Oeste $(28,62 \%)$.

As IES precisam prever e oferecer condições de acessibilidade, para que, depois do ingresso, sua permanência seja o menos conflitiva possível. Já no caso das pessoas com visão monocular, em alguns casos, não haverá necessidade de adequações no ambiente educacional, já que "Algumas realizam atividades escolares sem necessidade de nenhum auxílio, enquanto outras precisam de auxílios ópticos (lupas e telescópios), eletrônicos (lupas eletrônicas e vídeoampliadores) e de informática (software ampliadores e/ou leitores de telas) [...]" (BORGES, 2019, p. 27).

A cegueira é "definida pela acuidade visual igual ou menor que 0,05 no melhor olho, com a melhor correção óptica; ausência total de visão até a perda da percepção luminosa" (INEP, 2015, p. 42). Esses estudantes representavam 4,97\% do PAEE; a região com o menor percentual era a Norte $(3,36 \%)$ e com o maior, a Sul $(5,48 \%)$. Novamente, assim como na baixavisão, as variações são pequenas, mostrando uma distribuição mais uniforma dessa população na educação superior.

A cegueira é mais facilmente identificada, pois faz parte do rol de deficiências que são mais perceptíveis, que demandam diagnósticos clínicos mais precisos e objetivos. O problema para esse grupo consiste, por vezes, na demora para a emissão de laudos, pela especificidade de equipamentos oftalmológicos distribuídos heterogeneamente nas diferentes regiões.

O transtorno desintegrativo da infância (TID) é entendido como uma 
[...] regressão pronunciada em múltiplas áreas do funcionamento, caracteriza-se pela perda de funções e capacidades anteriormente adquiridas pela criança. Apresenta características sociais, comunicativas e comportamentais também observadas no autismo. Em geral, essa regressão tem início entre 2 e 10 anos de idade e acarreta alterações qualitativas na capacidade para relações sociais, jogos ou habilidades motoras, linguagem, comunicação verbal e não verbal, com comportamentos estereotipados e instabilidade emocional (INEP, 2015, p. 42).

Esse transtorno representava $0,25 \%$ das matrículas de estudantes PAEE, sendo que era na região Sudeste que quase $60 \%$ desses estudantes estava e, percentualmente, era essa a região com o maior índice $(0,43 \%)$. O menor percentual estava no Centro-Oeste $(0,13 \%)$.

Diferentemente do Transtorno do Espectro Autista (TEA), o TDI ocorre após o nascimento e o desenvolvimento global desses sujeitos ocorre atipicamente (MERCADANTE et al, 2006). "O TDI é uma condição extremamente rara. Fombonne revisou 32 pesquisas epidemiológicas sobre autismo e TDI. O TDI foi mencionado somente em quatro estudos" (Idem, p. 14). Assim, a literatura que trata sobre esse transtorno é restrita e demanda mais investigações, sobretudo no tocante a esses estudantes identificados na educação superior, que indicam a "raridade da raridade", ou seja, são duplamente raros, de um lado por ter tal transtorno e por outro por estar em um nível de educação que poucos alcançam diante de tais condições.

A deficiência física é

[...] definida pela alteração completa ou parcial de um ou mais segmentos do corpo humano, acarretando o comprometimento da função física, apresentando-se sob a forma de paraplegia, paraparesia, monoplegia, monoparesia, tetraplegia, tetraparesia, triplegia, triparesia, hemiplegia, hemiparesia, ostomia, amputação ou ausência do membro, paralisia cerebral, nanismo, membros com deformidade congênita ou adquirida, exceto as deformidades estéticas e as que não produzem dificuldades para o desempenho das funções (INEP, 2015, p. 42-43).

Os estudantes com deficiência física eram, entre o PAEE, aqueles que tinham maior quantitativo (12.638) e representavam 33,32\% das matrículas. O maior percentual estava na região Sudeste $(41,07 \%)$ e o menor, na região Nordeste $(23,79 \%)$. A deficiência física é composta por uma gama bastante grande de características, mas em um número significativo de casos as pessoas não apresentam dificuldades cognitivas, e, por essa razão, um grande número chega à educação superior. No entanto, “[...] existem inúmeras condições de deficiência física que vão exigir da universidade diferentes adaptações em seus espaços" (GESSER; NUERNBERG, 2017, p. 155).

A deficiência intelectual é "definida por alterações significativas, tanto no desenvolvimento intelectual como na conduta adaptativa, na forma expressa em habilidades práticas, sociais e conceituais” (INEP, 2015, p. 43). Na educação superior, esse público representava $3,86 \%$ das matrículas entre os estudantes PAEE e o maior percentual estava na 
região Centro-Oeste (16,46\%). Era nessa região que mais de $40 \%$ desses alunos com essas características estavam. O menor percentual, em comparação aos estudantes PAEE por região, estava na região Nordeste $(1,12 \%)$.

A deficiência intelectual é um desafio às IES, vez que o ambiente acadêmico é competitivo e isso gera exclusões, tanto por parte dos docentes, como dos próprios colegas de sala de aula. Assim, Ferrari e Sekkel (2007) asseveram que: "Se atentarmos para o histórico das universidades e seus desdobramentos em nosso país, perceberemos que seu ensino, tradicionalmente, é voltado para as elites econômicas e intelectuais, o que marca o espaço acadêmico como um lugar destinado aos privilegiados" (p. 644). Os autores relatam ainda que, em uma determinada sala de aula de um curso de graduação, os colegas de sala rejeitaram uma estudante com deficiência intelectual, com “[...] o temor de serem prejudicados nos trabalhos coletivos pelo baixo rendimento da colega" (p. 643). Vencida a barreira do ingresso a esses estudantes, a sua permanência na IES e sucesso acadêmico será derivativo do grande esforço que terá que ser empreendido na árdua tarefa do "pós-ingresso".

O PAEE com o menor percentual na educação superior brasileira era de estudantes com Síndrome de Rett, caracterizada como um

[...] transtorno de ordem neurológica e de caráter progressivo, com início nos primeiros anos de vida. Manifesta-se pela ausência de atividade funcional com as mãos, isolamento, regressão da fala e das habilidades motoras adquiridas, comprometimento das relações sociais, do desenvolvimento mental e microcefalia progressiva (INEP, 2015, p. 42).

Eram 19 estudantes com tais características em toda a educação superior e entre o PAEE eles representavam $0,05 \%$ das matrículas. O maior percentual desse público era encontrado na região Norte $(0,17 \%)$ e o menor, na região Sul (0,02\%). Entre o PAEE, em 2015, a Síndrome de Rett era a que apresentava o menor quantitativo, uma vez que: "[...] é uma condição particularmente desafiadora, tendo em vista a gravidade do comprometimento motor e cognitivo, repercutindo no nível de independência funcional [...]" (MONTEIRO et al., 2009, p. 342). Em um estudo conduzido com 64 pacientes com a referida síndrome, com idades entre 2 e 26 anos e 9 meses, observou-se que: "O desempenho nas áreas de função social e autocuidado manteve-se em valores muito baixos, mesmo em fases iniciais da doença” (p. 344) e que a habilidade mais preservada era a de mobilidade. Em outro estudo, a Síndrome de Rett em meninos é indicada ainda como mais rara e que: “[...] se aceita que a pesquisa de mutações no gene MECP2 esteja justificada em meninos com formas severas de encefalopatia que não tenham alguma etiologia claramente definida" (SCHWARTZMAN, 2003, p. 112). Nesse 
sentido, causam estranheza os dados do Censo da Educação Superior de 2015, que apontam que havia oito estudantes (do sexo masculino) com Síndrome de Rett, o que chama a atenção e indica a necessidade de averiguação da veracidade dessa informação.

As altas habilidades/superdotação são evidenciadas pelo "potencial elevado em qualquer uma das seguintes áreas, isoladas ou combinadas: intelectual, acadêmica, liderança, psicomotricidade e artes, além de apresentar grande criatividade, envolvimento na aprendizagem e realização de tarefas em áreas de seu interesse" (INEP, 2015, p. 42).

Esse público de estudantes representava $12,59 \%$ entre as matrículas do PAEE e a região mais representativa era a Nordeste ${ }^{\text {xiii }}(33,98 \%)$. Essa região tinha $83,64 \%$ de todas as matrículas de superdotados/altas habilidades na educação superior brasileira. O menor percentual era registrado na região Centro-Oeste $(2,03 \%)$ entre as matrículas de estudantes PAEE. O número baixo de estudantes com tais características se justifica. "Estudos internacionais demonstram que o porcentual de crianças superdotadas ou com altas habilidades varia de $10 \%$ a $15 \%$. No Brasil, as estatísticas apontam um número menor, devido às dificuldades de identificação[...]" (SCHENINI, 2020, s/p), ou seja, ainda estamos distantes de identificar tal público na educação superior de forma efetiva e, assim, estimular o potencial elevado desses estudantes. Além disso, chama a atenção a grande disparidade entre as regiões brasileiras para estudantes com altas habilidades/superdotação, o que pressupõe a necessidade de estudos mais pontuais para uma melhor investigação a esse respeito.

A surdez é caracterizada como a "perda auditiva acima de $71 \mathrm{~dB}$, aferida por audiograma nas frequências de $500 \mathrm{~Hz}, 1.000 \mathrm{~Hz}, 2.000 \mathrm{~Hz}$ e $3.000 \mathrm{~Hz}$ ” (INEP, 2015, p. 42). Esse público representava 4,27\% dentre o PAEE; sua maior representatividade estava na região Sudeste $(5,87 \%)$ e Sul $(5,85 \%)$ e a menor representatividade, na região Nordeste $(2,78 \%)$.

São estudantes usurários da língua brasileira de sinais (Libras), implicando uma relação de diferença linguística no contexto universitário, no qual a língua de circulação da maioria (língua portuguesa) difere, quanto à modalidade e estrutura, da Libras. Em pesquisa realizada com estudantes da Universidade Federal de Santa Maria (UFSM), Rocha e Santos (2017) identificaram, nas relações presentes de estudantes surdos com seus professores ouvintes em sala de aula, que há: “[...] falta de interesse destes no aprendizado da língua de sinais, [...] falta de compreensão destes quanto ao uso de recursos visuais e à disponibilização de tempo extra e à correção diferenciada dos aspectos semânticos dos alunos surdos nas avaliações escritas" (p. 840). Ou seja, apesar da garantia do ingresso, a permanência ainda é algo 
conflituoso nas relações diárias do estudante com todos os personagens presentes no cenário da inclusão.

A surdocegueira constitui “deficiência única, caracterizada pela deficiência auditiva e visual concomitante. Essa condição apresenta outras dificuldades além daquelas causadas pela cegueira e pela surdez" (INEP, 2015, p. 42). É um público bastante pequeno na educação superior e representava entre as matrículas $0,24 \%$. A região com o maior percentual de surdocegos era a região Norte $(0,81 \%)$, e a menor, a região Centro-Oeste $(0,08 \%)$, o que demostrar bastante variação.

As pesquisas que relacionam surdocegueira e educação superior são escassas. Um desses estudos é de Muccini (2017), que assevera sobre a necessidade de as IES oferecerem ao quadro de docentes "[...] formação acerca das especificidades da surdocegueira e dos recursos sociocomunicacionais disponíveis para a inclusão desse grupo [...]" (p. 97) e relata que: "[...] ainda é desafiador estruturar uma instituição acessível para estudantes que possuem surdocegueira, considerando que suas características e especificidades fogem do escopo habitual do corpo discente no ensino superior [...]" (p. 36).

A deficiência múltipla, no glossário do aluno, é explicada “[...] pela associação de dois ou mais tipos de deficiência (intelectual/visual/auditiva/física)” (INEP, 2015, p. 43). Esse público de estudantes representava 1,14\% das matrículas entre o PAEE. Entre as regiões, o maior percentual estava na região Norte $(1,76 \%)$, e o menor, na região Nordeste $(0,86 \%)$.

Aráoz et al. (2011) endossam “[...] a importância da interdisciplinaridade e a articulação dos recursos necessários para que a inclusão das pessoas com deficiência seja concretizada, que no caso da inclusão de pessoas com deficiência múltipla é imprescindível" (p. 3046).

A associação de características do PAEE não está prevista no glossário do aluno, no entanto, foi uma categoria criada por nós ${ }^{\mathrm{xiv}}$, para nos referirmos às mais de 60 distintas combinações, quando da marcação da deficiência dos estudantes. Em alguns casos, essas condições poderiam ser marcadas como deficiência múltipla, no entanto, o pesquisador institucional (que fornece as informações para o Censo) não o faz, marcando cada característica separadamente. Essa possibilidade de informar constitui um "erro de sistema", bem como um erro no entendimento de quem informou os dados. Assim, por exemplo, a marcação: surdez+deficiência física+baixa-visão deveria ser informada como estudante com deficiência múltipla. Havia 1,63\% das matrículas com preenchimento desse tipo entre os estudantes PAEE, 
sendo a região Centro-Oeste $(3,87 \%)$ aquela com o maior percentual, e a região Nordeste $(0,44 \%)$, o menor.

Analisando pormenorizadamente, ficam evidentes algumas discrepâncias entre as regiões brasileiras no que diz respeito à distribuição do PAEE. Esses resultados podem indicar a necessidade de revisão e de implementação de políticas públicas, buscando um melhor atendimento e inserção social desse público, relativo a cada uma das regiões brasileiras no tocante à educação superior.

A inclusão crescente do PAEE vem modificar as instituições, não só no que se refere à estrutura física, mas também em aspectos relativos a questões comunicacionais, atitudinais e outras barreiras, antes não percebidas. As instituições assumiam um certo padrão de funcionamento e de estudantes que começa a ser transformado quando o PAEE chega à Educação Superior (GESSER, NUERNBERG, 2017; FERRARI, SEKKEL, 2007; MUCCINI, 2017; ARÁOZ et al., 2011).

O que tem sido observado, muitas vezes, quando da inclusão de estudantes com deficiência, é uma formação que se processa em serviço (ALCOBRA, 2008; PIECZKOWSKI, 2014), que tem sido "apontada pela literatura, pelos coordenadores de serviços de educação especial das secretarias municipais de ensino e pelo próprio Governo Federal como uma alternativa para a formação de professores para a Educação Inclusiva" (NOIZ; VITALIANO, 2015, p. 139). Acrescenta-se, ainda, que essa formação em serviço alcança, além de gestores e professores, os demais estudantes, que aprendem conjuntamente com o seu colega que é PAEE (ROCHA, SANTOS, 2017; FERRARI, SEKKEL, 2007), sobretudo quando a síndrome (MONTEIRO et al., 2009; SCHWARTZMAN, 2003), transtorno (MERCADANTE et al., 2006) ou deficiência (MUCCINI, 2017; ARÁOZ et al., 2011) é algo bastante raro nesse nível de ensino, com pouca ou nenhuma experiência anterior por parte da IES na inclusão. Assim, todos passam a ser aprendizes nesse processo educacional.

Do total de estudantes da educação superior, apenas $65,07 \%$ se autodeclararam no tocante a cor ou raça, o que pode não evidenciar um panorama legítimo da realidade nesse quesito, uma vez que a declaração pelo próprio sujeito está envolta por traços subjetivos e aspectos sociais, culturais e econômicos, que, portanto, precisam ser considerados no âmbito das análises (OSORIO, 2003; PANIZZ, 2016). Assim salienta Regueira (2004): "Possivelmente o indivíduo considerado como pardo no Rio Grande do Sul seria considerado branco na Bahia" (p. 79). Todavia, os dados disponíveis apresentam características ímpares, que nos permitem 
análises interessantes, sobretudo no panorama dos estudantes PAEE em comparação às matrículas no geral.

Tabela 3 - Cor ou raça dos estudantes PAEE e matrículas no geral - Brasil - 2015

\begin{tabular}{|c|c|c|c|c|c|c|c|c|c|c|}
\hline \multirow{2}{*}{$\begin{array}{l}\text { Brasil e } \\
\text { Regiões }\end{array}$} & \multicolumn{5}{|c|}{ PAEE** } & \multicolumn{5}{|c|}{ Geral } \\
\hline & Branco & Preto & Pardo & Amar & Indig & Branco & Preto & Pardo & Amar & Indig* \\
\hline \multirow{3}{*}{ Brasil } & 14.909 & 4.254 & 9.650 & 705 & 289 & 2.903 .256 & 429.632 & 1.743 .002 & 116.036 & 32.147 \\
\hline & $100 \%$ & $100 \%$ & $100 \%$ & $100 \%$ & $100 \%$ & $100 \%$ & $100 \%$ & $100 \%$ & $100 \%$ & $100 \%$ \\
\hline & $39,31 \%$ & $11,22 \%$ & $25,44 \%$ & $1,86 \%$ & $0,76 \%$ & $36,17 \%$ & $5,35 \%$ & $21,71 \%$ & $1,45 \%$ & $0,4 \%$ \\
\hline \multirow{3}{*}{ Norte } & 334 & 163 & 1.699 & 40 & 9 & 86.306 & 28.229 & 276.234 & 11.707 & 8.315 \\
\hline & $2,24 \%$ & $3,83 \%$ & $17,6 \%$ & $5,67 \%$ & $3,11 \%$ & $2,97 \%$ & $6,57 \%$ & $15,85 \%$ & $10,09 \%$ & $25,87 \%$ \\
\hline & $11,33 \%$ & $5,53 \%$ & $57,61 \%$ & $1,36 \%$ & $0,31 \%$ & $13,33 \%$ & $4,36 \%$ & $42,65 \%$ & $1,81 \%$ & $1,28 \%$ \\
\hline \multirow{3}{*}{ Nordeste } & 3.135 & 2.645 & 3.489 & 174 & 184 & 312.159 & 122.142 & 517.442 & 23.374 & 9.307 \\
\hline & $21,02 \%$ & $62,17 \%$ & $36,15 \%$ & $24,68 \%$ & $63,66 \%$ & $10,75 \%$ & $28,43 \%$ & $29,69 \%$ & $20,14 \%$ & $28,95 \%$ \\
\hline & $26,68 \%$ & $22,51 \%$ & $29,69 \%$ & $1,48 \%$ & $1,57 \%$ & $18,42 \%$ & $7,21 \%$ & $30,53 \%$ & $1,38 \%$ & $0,55 \%$ \\
\hline \multirow{3}{*}{ Sudeste } & 5760 & 934 & 2.647 & 272 & 62 & 1.500 .784 & 202.345 & 637.358 & 55.989 & 9.272 \\
\hline & $38,63 \%$ & $21,96 \%$ & $27,43 \%$ & $38,58 \%$ & $21,45 \%$ & $51,69 \%$ & $47,1 \%$ & $36,57 \%$ & $48,25 \%$ & $28,84 \%$ \\
\hline & $44,55 \%$ & $7,22 \%$ & $20,47 \%$ & $2,1 \%$ & $0,48 \%$ & $41,47 \%$ & $5,59 \%$ & $17,61 \%$ & $1,55 \%$ & $0,26 \%$ \\
\hline \multirow{3}{*}{ Sul } & 4416 & 247 & 583 & 126 & 19 & 783.649 & 31.725 & 89.075 & 10.053 & 1.974 \\
\hline & $29,62 \%$ & $5,8 \%$ & $6,04 \%$ & $17,87 \%$ & $6,57 \%$ & $26,99 \%$ & $7,38 \%$ & $5,11 \%$ & $8,66 \%$ & $6,14 \%$ \\
\hline & $67,93 \%$ & $3,8 \%$ & $8,97 \%$ & $1,94 \%$ & $0,29 \%$ & $59,77 \%$ & $2,42 \%$ & $6,79 \%$ & $0,77 \%$ & $0,15 \%$ \\
\hline \multirow{3}{*}{$\begin{array}{l}\text { Centro- } \\
\text { Oeste }\end{array}$} & 1264 & 265 & 1232 & 93 & 15 & 220.358 & 45.191 & 222.893 & 14.913 & 3.279 \\
\hline & $8,48 \%$ & $6,22 \%$ & $12,76 \%$ & $13,19 \%$ & $5,19 \%$ & $7,59 \%$ & $10,52 \%$ & $12,79 \%$ & $12,85 \%$ & $10,2 \%$ \\
\hline & $33,28 \%$ & $6,98 \%$ & $32,44 \%$ & $2,45 \%$ & $0,39 \%$ & $29,18 \%$ & $5,98 \%$ & $29,52 \%$ & $1,97 \%$ & $0,43 \%$ \\
\hline
\end{tabular}

* Há ainda os que não declararam sua cor ou raça: 2.412 .449 (30,05\%) e aqueles sobre os quais o censo não dispõe de tal informação: 390.775 (4,85\%), sendo estes "desconsiderados" da planilha (não havendo uma coluna para eles). No entanto, são devidamente contados no cálculo das porcentagens quanto aos percentuais da linha.

** Dos estudantes PAEE, os que não declararam sua cor ou raça foram $7.263(19,15 \%)$, e aqueles estudantes sobre os quais o censo não dispõe de tal informação somam 857 (2,26\%).

Fonte: Elaborada pelos autores com dados de Inep (2015).

Vale ressaltar que a marcação da opção "não quis declarar cor ou raça", segundo o Inep (2015), deve ser realizada em função daqueles "[...]alunos que foram expressamente consultados sobre sua declaração e optaram por não informar" (p. 39). No entanto, dado o alto número dos que não declaram tal informação, parece pouco provável que de fato tenham sido consultados individualmente. No Censo Demográfico (IGBE, 2010), apenas 0,02\% dos entrevistados não declararam tal informação, em um conjunto de pessoas entrevistadas muito superior ao Censo da Educação Superior.

Pela análise da tabela anterior, fica evidente que a maior diferença entre os estudantes PAEE e as matrículas no geral está na cor/raça preta. Nas matrículas no geral, esses estudantes representam 5,35\% das matrículas, já para os estudantes PAEE, essa raça/cor corresponde a 11,22\% das matrículas (o dobro), indicando maior predomínio desta, nesse público, proporcionalmente. No gráfico seguinte, explicita-se melhor essa questão. 


\section{Gráfico 1 - Cor ou raça dos estudantes da educação superior: geral e PAEE - Brasil - 2015}

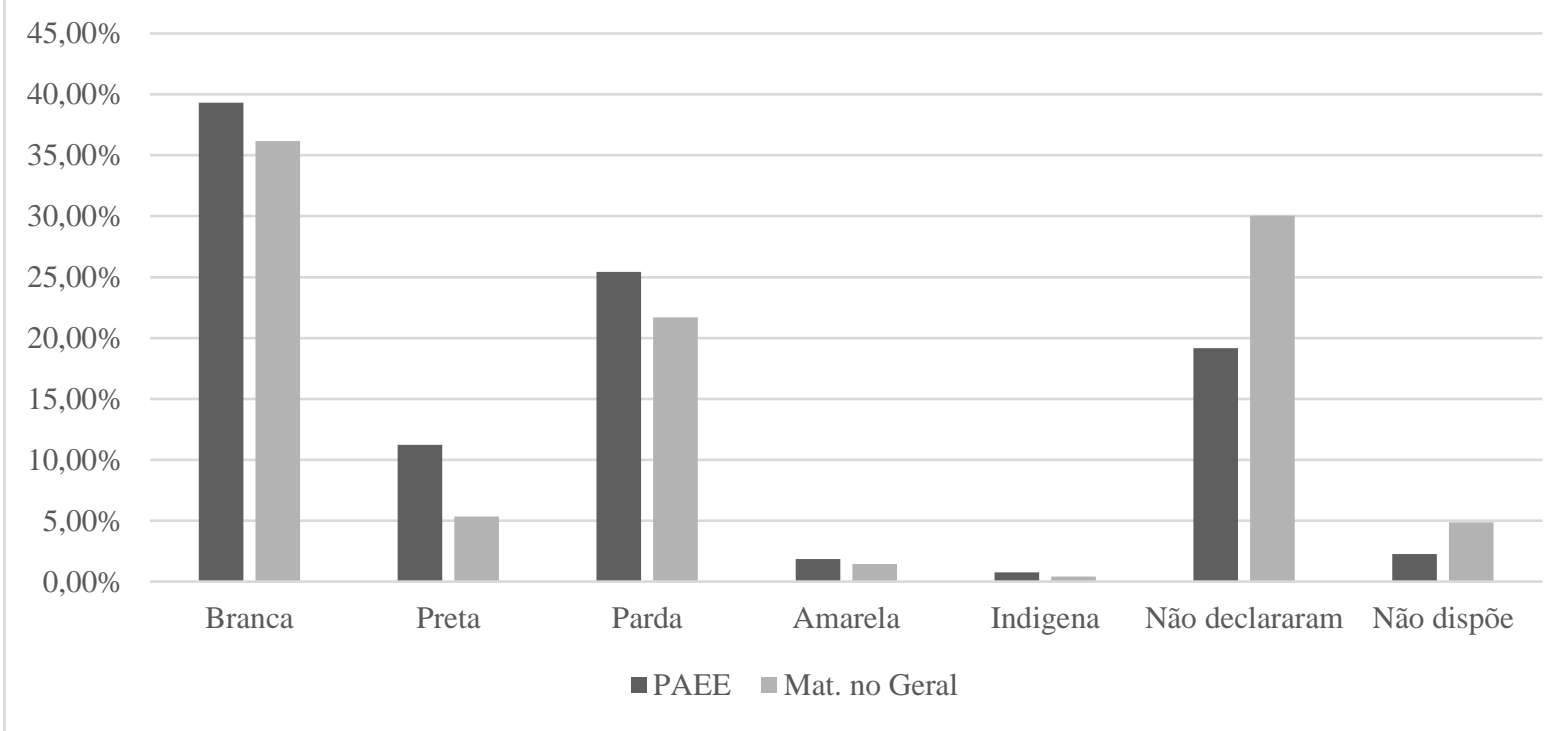

Fonte: Elaborado pelos autores com dados do Inep (2015).

Vale ressaltar que, na população brasileira, há cerca de 47,5\% de pessoas brancas, 43,42\% pardas, $7,52 \%$ pretas, $1,1 \%$ amarelas e 0,43\% indígenas (IBGE, 2010). Ou seja, se pensarmos que nas IES essas mesmas proporções deveriam ser espelhadas, ainda temos importantes distorções a serem superadas. Nesse sentido, a coleta dessa informação merece aprimoramento para que os dados do Inep (2015) expressem um panorama mais fidedigno, permitindo análises ainda mais apuradas no que se refere à realidade no quesito raça/cor dos estudantes.

Ao que parece, ao analisar a raça/cor preta e a indígena, há “[...] uma tendência em favorecer grupos mais excluídos socialmente, indicando que ações desse tipo podem estar mudando o quadro de ingresso à Educação Superior, que tem se tornado cada vez mais heterogêneo [...]" (ROCHA, 2019, p. 149). Ou seja, a análise dos dados parece indicar que ser de raça/cor preta e pessoa com deficiência confere uma maior probabilidade em alcançar a educação superior, talvez indicando um resultado que poderia ser atribuído às políticas afirmativas de cotas para pretos nesse nível de ensino. Isso também ocorre em relação à raça/cor indígena, para a qual o percentual de estudantes PAEE é o dobro em relação às matrículas no geral, proporcionalmente. Ser indígena e ter uma deficiência incorre em uma dupla luta pela sobrevivência (BRUNO; SOUZA, 2014), bem como em uma dupla exclusão, assim como ocorre como os estudantes pretos. Por essa razão, as políticas de ações afirmativas são fundamentais para o alcance desses resultados, aumentando a probabilidade de ingresso desses grupos diuturnamente duplamente excluídos. 
Ainda na perspectiva de traçar um perfil do PAEE, algo que ajudará na composição dessas cenas é a idade com que os estudantes PAEE está chegando e/ou permanecendo na educação superior, conforme tabela seguinte.

Tabela 4 - Idade dos estudantes PAEE e matrículas no geral - Brasil - 2015

\begin{tabular}{|c|c|c|c|c|c|c|c|c|}
\hline \multirow{2}{*}{$\begin{array}{l}\text { Brasil e } \\
\text { Regiões }\end{array}$} & \multicolumn{4}{|c|}{ PAEE } & \multicolumn{4}{|c|}{ Geral } \\
\hline & $\begin{array}{l}\text { Até } 18 \\
\text { anos }\end{array}$ & $\begin{array}{l}\text { De } 19 \text { a } \\
24 \text { anos }\end{array}$ & $\begin{array}{l}\text { De } 25 \text { a } \\
29 \text { anos }\end{array}$ & $\begin{array}{l}30 \text { anos } \\
\text { ou mais }\end{array}$ & $\begin{array}{l}\text { Até } 18 \\
\text { anos }\end{array}$ & $\begin{array}{c}\text { De } 19 \text { a } 24 \\
\text { anos }\end{array}$ & $\begin{array}{c}\text { De } 25 \text { a } 29 \\
\text { anos }\end{array}$ & $\begin{array}{c}30 \text { anos ou } \\
\text { mais }\end{array}$ \\
\hline \multirow{3}{*}{ Brasil } & 1.409 & 15.487 & 7.125 & 13.906 & 365.830 & 3.737 .920 & 1.609 .966 & 2.313 .581 \\
\hline & $100 \%$ & $100 \%$ & $100 \%$ & $100 \%$ & $100 \%$ & $100 \%$ & $100 \%$ & $100 \%$ \\
\hline & $3,72 \%$ & $40,83 \%$ & $18,79 \%$ & $36,67 \%$ & $4,56 \%$ & $46,57 \%$ & $20,06 \%$ & $28,82 \%$ \\
\hline \multirow{3}{*}{ Norte } & 75 & 882 & 591 & 1.401 & 26.180 & 263.882 & 128.791 & 228.756 \\
\hline & $5,32 \%$ & $5,7 \%$ & $8,29 \%$ & $10,07 \%$ & $7,16 \%$ & $7,06 \%$ & $8 \%$ & $9,89 \%$ \\
\hline & $2,54 \%$ & $29,91 \%$ & $20,04 \%$ & $47,51 \%$ & $4,04 \%$ & $40,75 \%$ & $19,89 \%$ & $35,32 \%$ \\
\hline \multirow{3}{*}{ Nordeste } & 636 & 5.883 & 2.000 & 3.232 & 76.786 & 761.312 & 354.647 & 501.935 \\
\hline & $45,14 \%$ & $37,99 \%$ & $28,07 \%$ & $23,24 \%$ & $20,99 \%$ & $20,37 \%$ & $22,03 \%$ & $21,7 \%$ \\
\hline & $5,41 \%$ & $50,06 \%$ & $17,02 \%$ & $27,5 \%$ & $4,53 \%$ & $44,92 \%$ & $20,93 \%$ & $29,62 \%$ \\
\hline \multirow{3}{*}{ Sudeste } & 318 & 4.428 & 2.497 & 5.685 & 145.208 & 1.717 .049 & 731.165 & 1.025 .289 \\
\hline & $22,57 \%$ & $28,59 \%$ & $35,05 \%$ & $40,88 \%$ & $39,69 \%$ & $45,94 \%$ & $45,41 \%$ & $44,32 \%$ \\
\hline & $2,46 \%$ & $34,25 \%$ & $19,31 \%$ & $43,97 \%$ & $4,01 \%$ & $47,45 \%$ & $20,21 \%$ & $28,33 \%$ \\
\hline \multirow{3}{*}{ Sul } & 261 & 2.862 & 1.277 & 2.101 & 77.322 & 636.352 & 254.749 & 342.778 \\
\hline & $18,52 \%$ & $18,48 \%$ & $17,92 \%$ & $15,11 \%$ & $21,14 \%$ & $17,02 \%$ & $15,82 \%$ & $14,82 \%$ \\
\hline & $4,01 \%$ & $44,02 \%$ & $19,64 \%$ & $32,32 \%$ & $5,9 \%$ & $48,53 \%$ & $19,43 \%$ & $26,14 \%$ \\
\hline \multirow{3}{*}{$\begin{array}{l}\text { Centro- } \\
\text { Oeste }\end{array}$} & 119 & 1.432 & 760 & 1.487 & 40.334 & 359.325 & 140.614 & 214.823 \\
\hline & $8,45 \%$ & $9,25 \%$ & $10,67 \%$ & $10,69 \%$ & $11,03 \%$ & $9,61 \%$ & $8,73 \%$ & $9,29 \%$ \\
\hline & $3,13 \%$ & $37,7 \%$ & $20,01 \%$ & $39,15 \%$ & $5,34 \%$ & $47,59 \%$ & $18,62 \%$ & $28,45 \%$ \\
\hline
\end{tabular}

Fonte: Elaborada pelos autores com dados do Inep (2015).

Mais de 50\% das matrículas no geral são de estudantes com idade entre 18 e 24 anos. Para os estudantes PAEE, esse percentual gira em torno de 44,5\%. O Plano Nacional de Educação (PNE) apresenta que o objetivo fim é: "Elevar a taxa bruta ${ }^{\mathrm{xv}}$ de matrícula na Educação Superior para $50 \%$ e a taxa líquida para $33 \%$ da população de 18 a 24 anos, assegurada a qualidade da oferta e expansão para, pelo menos, $40 \%$ das novas matrículas, no segmento público" (BRASIL, 2014). Desse modo, Amaral (2016, p. 723) esclarece:

O Censo Demográfico de 2010 apresentou o Brasil com uma população total de 190.757.799 habitantes; desses, 23.878.190 são jovens com idade entre 18 e 24 anos e que estariam, portanto, na idade adequada para realizar um curso de graduação. Entretanto, o Censo da Educação Superior relativo ao ano de 2011 informa-nos que estão matriculados 6.739 .689 estudantes - adicionando-se alunos de cursos presenciais e a distância -, sendo que apenas 3.411 .050 estão com idade de 18 a 24 anos. Temos, portanto, uma taxa líquida de $14,3 \%$ e uma taxa bruta de $28,2 \%$.

Entre as regiões, temos que os estudantes com a idade mais adequada, conforme pressupostos da Unesco, estavam na região Sul: 54,43\% e o maior PAEE estava na região Nordeste, a qual tinha cerca de 55\% dos seus estudantes entre 18 e 24 anos. No geral, com idade menos adequada estava a região Norte, uma vez que mais de 55\% dos seus estudantes tinham 
mais de 24 anos de idade. Nessa região, o PAEE com a idade menos adequada chegava a mais de $65 \%$.

No gráfico 3 podem ser visualizadas de forma bastante clara algumas disparidades já elencadas.

\section{Gráfico 2 - Idade dos estudantes da educação superior: PAEE e geral - Brasil - 2015}

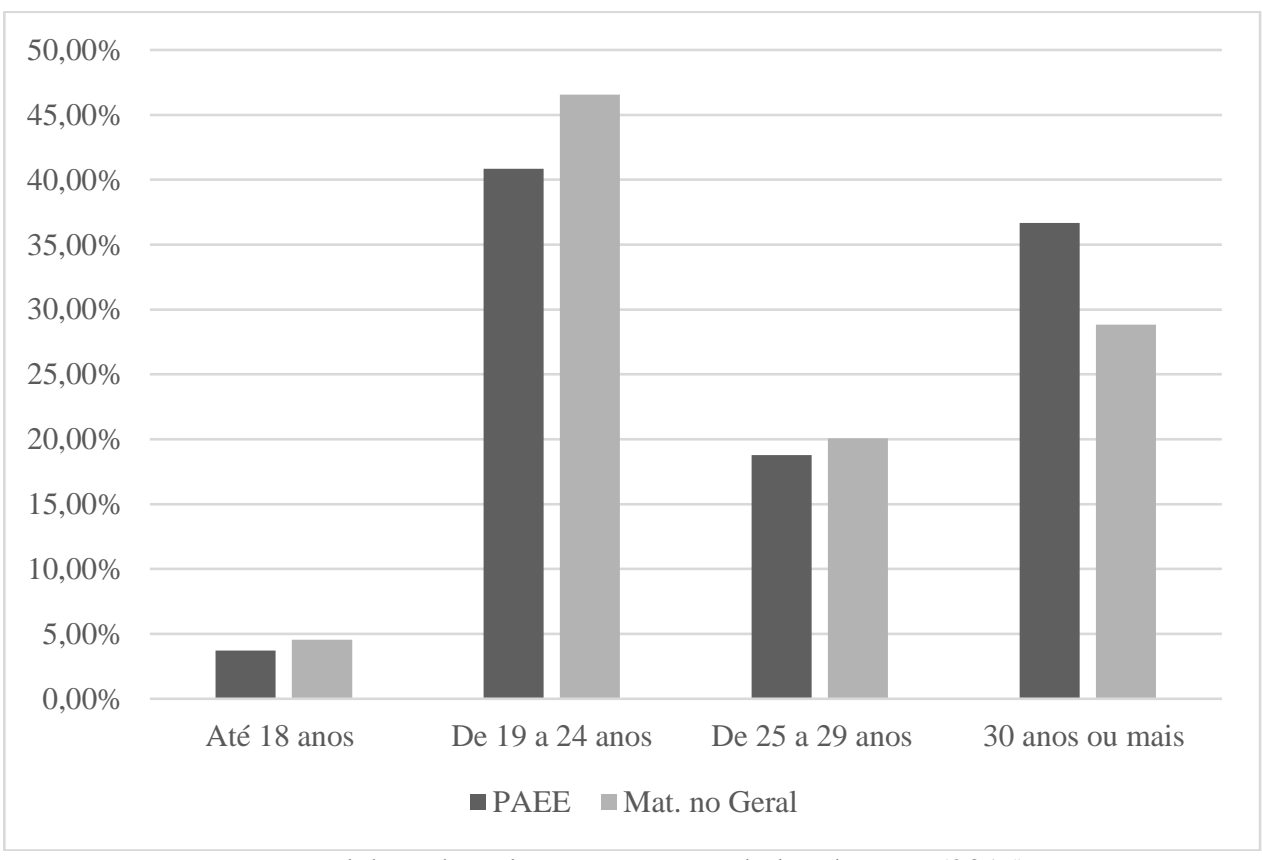

Fonte: Elaborado pelos autores com dados do Inep (2015).

Nesse contexto, Rocha (2019) esclarece que uma das possíveis razões para um PAEE com idade menos adequada que nas matrículas no geral seja "um cenário menos propício a esses estudantes, ocasionado, talvez, por uma trajetória escolar complexa, com uma Educação Básica que não atende suas necessidades específicas, resultando, assim, em uma distorção idade-série" (p. 162). Santos (2017) destaca em sua pesquisa que, apesar de os "[...] índices de defasagem serem reduzidos nos anos finais do ensino fundamental e no ensino médio, somente uma pequena porcentagem de alunos PAEE alcança estas etapas, o que fortalece a evidência de ineficiência dos serviços de apoio oferecidos [...]" (p. 96), impactando o avanço na vida escolar.

Além disso, é possível encontrar na literatura que os estudantes PAEE, por vezes, estão permanecendo mais tempos nas IES, por não ser oferecido a esse público o atendimento adequado às suas especificidades (SILVEIRA, 2015; URBAN, 2016), seja pela pouca preparação dos docentes no tocante à temática da inclusão, seja por políticas institucionais pouco efetivas e, por vezes, inexistentes nas IES. 


\section{Considerações finais}

Traçar um panorama dos estudantes PAEE colabora para dar visibilidade a esse grupo, que, historicamente, começa a ter seu ingresso na educação superior de forma mais efetiva recentemente. Essa exclusão histórica passa a ser enfrentada por sujeitos PAEE e outras pessoas sem deficiência, que comungam sobre essa perspectiva inclusiva das IES. Conhecer quem são, onde estão e suas características é fundamental para a ampliação de ações que tornem a educação superior um espaço de aprendizagem e formação desse público e, ainda, para revelar a necessidade de criação de mais políticas públicas, para tornar essa modalidade de ensino cada vez mais inclusiva.

Por meio das análises realizadas nos microdados do Censo da Educação Superior brasileira, foi possível identificar várias características dos estudantes PAEE e, assim, traçar seu perfil nesse nível de ensino. Fica evidente, por exemplo, que faltam políticas públicas mais efetivas para o ingresso desse público, haja vista sua presença ser de apenas $0.47 \%$ das matrículas no geral. Sabemos que, com a lei de reserva de vagas (BRASIL, 2016), o cenário da educação superior poderá ser alterado, e, assim, necessário se faz que se trace um perfil nos próximos anos, buscando analisar os impactos no tocante à obrigatoriedade na reserva das vagas às pessoas com deficiência nas IFES.

O dado relativo à cor ou raça é bastante complexo de se analisar, uma vez que muitas IES declaram não ter disponíveis os dados dos estudantes, o que as desobriga da declaração de tais informações. Entretanto, é possível perceber que as variações entre os estudantes e os dados coletados pelo IBGE são convergentes e a maior disparidade está no conjunto de estudantes PAEE pretos e indígenas, uma vez que há um percentual acima da média nas IES em comparação aos estudantes no geral (proporcionalmente), o que pode indicar efeitos de políticas públicas de ações afirmativas a essa população, que tem sido duplamente excluída.

$\mathrm{Na}$ variável idade, o PAEE está chegando mais tarde às IES e/ou permanecendo mais tempo, pois estão em uma idade menos adequada para esse nível de ensino. Tal informação tem apontado que políticas públicas mais efetivas para o PAEE são necessárias, uma vez que esse público pode estar chegando tardiamente na IES, reflexos de uma educação básica pouco atenta às suas necessidades.

Ao analisar o PAEE por regiões brasileiras, fica claro que existem disparidades, por vezes grandes, e outras que convergem às matrículas no geral; e, se analisados os estados 
brasileiros, as disparidades são ainda maiores e mostram que pesquisas cada vez mais pontuais merecem ser realizadas.

Concluímos que pesquisas que congregam um volume grande de dados e traçam perfis de determinados públicos podem apontar para o avanço de políticas públicas nesse campo e, assim, é possível que públicos, muitas vezes alijados por uma educação pouco atenta às suas diferenças, sejam vistos e percebidos como sujeitos ativos e que, portanto, precisam ser alcançados pelos princípios de uma educação inclusiva.

\section{Referências}

AMARAL, Nelson Cardoso. A Educação Superior brasileira: dilemas, desafios e comparações com os países da OCDE e do BRICS. Rev. Bras. Educ., Rio de Janeiro, v. 21, n. 66, p. 717-736, Set. 2016.

ARAÓZ, S. M.M.; Cambruzzi, R. de. C. S; COSTA, M. P. R. da; SOUZA, C. T.; SOUZA, G. M. de; Inclusão na Deficiência Múltipla em Instituição de Ensino Superior particular no Estado de Rondônia. In: 5, CONGRESSO BRASILEIRO MULTIDISCIPLINAR DE EDUCAÇÃO ESPECIAL e ENCONTRO DA ASSOCIAÇÃO BRASILEIRA DE PESQUISADORES EM EDUCAÇÃO ESPECIAL Anais... . Londrina, 2011. p. 3040-3048. BORGES, Wanessa Ferreira. O uso de dispositivos eletrônicos móveis como tecnologia assistiva por pessoas com baixa visão. 2019. Tese (Doutorado) - Programa de PósGraduação em Educação Especial, Universidade Federal de São Carlos, São Carlos, São Paulo, 2019.

BRASIL. CONSELHO NACIONAL DE SAÚDE (CNS). Resolução n 466, de 12 de dezembro de 2012. Diário Oficial da União, Brasília, DF, 13 jun. 2013, seção 1, p. 59. BRASIL. Decreto $n^{\circ}$ 7.234, de 19 de julho de 2010. Dispõe sobre o Programa Nacional de Assistência Estudantil - PNAES. Diário Oficial da União, Brasília-DF, 20 jul. 2010, seção 1, p. 5.

BRASIL. Decreto $n^{\circ} 7.611$, de 17 de novembro de 2011. Dispõe sobre a educação especial, o atendimento educacional especializado e dá outras providências. Diário Oficial da União, Brasília-DF, 18 nov. 2011, seção 1, p. 12. Diário Oficial da União, Brasília-DF, Edição Extra, 18 nov. 2011, Seção 1, Página 5 (Republicação).

BRASIL. Lei no 10.861, de 14 de abril de 2004. Lei do Sinaes; Lei do Sistema Nacional de Avaliação da Educação Superior. Institui o Sistema Nacional de Avaliação da Educação Superior - SINAES e dá outras providências. Diário Oficial da União, Brasília-DF, 15 abr. 2004, seção 1, p. 3.

BRASIL. Lei $\mathrm{n}^{\circ}$ 12.711, de 29 de agosto de 2012. Lei de Cotas de Ingresso nas Universidades; Lei de Cotas nas Universidades; Lei de Cotas Sociais. Dispõe sobre o ingresso nas universidades federais e nas instituições federais de ensino técnico de nível médio e dá outras providências. Diário Oficial da União, Brasília-DF, 30 ago. 2012, seção 1, p. 1. BRASIL. Lei no 13.005, de 25 de junho de 2014. Aprova o Plano Nacional de Educação PNE e dá outras providências. Diário Oficial da União, Brasília-DF, Edição Extra, 26 jun. 2014a, seção 1, p. 1.

BRASIL. Lei n ${ }^{\circ}$ 13.146, de 6 de julho de 2015. Estatuto da Pessoa com Deficiência. Lei Brasileira de Inclusão da Pessoa com Deficiência. Institui a Lei Brasileira de Inclusão da Pessoa com Deficiência (Estatuto da Pessoa com Deficiência). Diário Oficial da União, Brasília, seção 1, 7 jul. 2015, p. 2. 
BRASIL. Lei $\mathrm{n}^{\circ} 13.409$, de 28 de dezembro de 2016. Altera a Lei $\mathrm{n}^{\mathrm{o}} 12.711$, de 29 de agosto de 2012, para dispor sobre a reserva de vagas para pessoas com deficiência nos cursos técnico de nível médio e superior das instituições federais de ensino. Diário Oficial da União, Brasília-DF, 29 dez. 2016, seção 1, p. 3.

BRUNO, M. M. G.; SOUZA, V. P. Crianças Indígenas Kaiowá e Guarani: um estudo sobre as representações sociais da deficiência. Revista de Educação Pública (UFMT), v. 23, p. 425440, 2014.

CANTORANI, José Roberto Herrera; PILATTI, L. A.; HELMANN, C. L.; SILVA, S. C. R. da. Acessibilidade e a inclusão em uma Instituição Federal de Ensino Superior a partir da lei n. 13.409. Rev. Bras. Educ., Rio de Janeiro, v. 25, 2020.

DURHAM, Eunice Ribeiro. O ensino superior no Brasil: público e privado. São Paulo: Núcleo de Pesquisas sobre Ensino Superior da USP, 2003.

FERRARI, Marian A. L. Dias; SEKKEL, Marie Claire. Educação inclusiva no ensino superior: um novo desafio. Psicol. cienc. prof. [online]. 2007, vol. 27, n. 4, p. 636-647. GESSER, Marivete; NUERNBERG, Adriano Henrique. A participação dos estudantes com deficiência física e visual no ensino superior: apontamentos e contribuições das teorias feministas da deficiência. Educ. rev. [online]. 2017, v. 3, p.151-166.

INSTITUTO BRASILEIRO DE GEOGRAFIA E ESTATÍSTICA (IBGE). Metodologia do Censo Demográfico 2010. Rio de Janeiro: IBGE, 2016b. Disponível em:

<http://biblioteca.ibge.gov.br/visualizacao/livros/liv95987.pdf>. Acesso em: 31 de mar. 2019. INSTITUTO NACIONAL DE ESTUDOS E PESQUISAS EDUCACIONAIS ANÍSIO TEIXEIRA (INEP). Censo da Educação Superior: 2015. Brasília: MEC/Inep, 2015. MARTINS, Diléia Aparecida; LEITE, Lúcia Pereira; LACERDA, Cristina Broglia Feitosa de. Políticas públicas para acesso de pessoas com deficiência ao ensino superior brasileiro: uma análise de indicadores educacionais. Ensaio (Rio de Janeiro. Online), v. 23, p. 984-1014, 2015.

MERCADANTE, Marcos T; VAN DER GAAG, Rutger J; SCHWARTZMAN, Jose S. Transtornos invasivos do desenvolvimento não-autísticos: síndrome de Rett, transtorno desintegrativo da infância e transtornos invasivos do desenvolvimento sem outra especificação. Rev. Bras. Psiquiatr., 2006, v. 28, supl. 1, p. 12-20.

MONTEIRO, Carlos Bandeira de Mello; GRACIANI, Zodja; TORRIANI, Camila; KOK, Fernando. Caracterização das habilidades funcionais na síndrome de Rett. Fisioter.

Pesqui. [online]. 2009, v.16, n.4, p.341-345.

MUCCINI, Patrícia. Estudantes com surdocegueira na universidade: mapeando barreiras e facilitadores que perpassam o processo de inclusão acadêmica. 2017. Dissertação (Mestrado) Programa Pós-Graduação em Psicologia, Universidade Federal de Santa Catarina,

Florianópolis, Santa Catarina, 2017.

OSORIO, R. G. O sistema classificatório de "cor ou raça” do IBGE. Brasília: IPEA, 2003. 50 p. Texto para discussão n. 996.

PANIZZ, C. S.; A autodeclaração como técnica de identificação racial no direito brasileiro. In: 22, SEMANA DE EXTENSÃO, PESQUISA E PÓS-GRADUAÇÃO - SEPesq, 2016, Porto Alegre. Anais.... v. 1., p. 1-12.

PINTO, José Marcelino de Rezende. O acesso à Educação Superior no Brasil. Educ. Soc., Campinas, v. 25, n. 88, p. 727-756, Out. 2004.

REGUEIRA, Aparecida Tereza Rodrigues. As fontes estatísticas em relações raciais e a natureza da investigação do quesito cor nas pesquisas sobre a população no Brasil: contribuição para os estudos das desigualdades raciais na educação. 2004. 239 p. Dissertação (Mestrado) - Programa de Pós-Graduação em Educação, Universidade Estadual do Rio de Janeiro, Rio de Janeiro, 2004. 
ROCHA, Luiz Renato Martins; SANTOS, Lara Ferreira. O que dizem os estudantes surdos da Universidade Federal de Santa Maria sobre a sua permanência no ensino superior. Práxis Educativa [Online], v. 12, p. 826-847, 2017.

ROCHA, Luiz Renato Martins. Panorama nacional dos estudantes público-alvo da educação especial na educação superior. 2019. 276 f. Tese (Doutorado em Educação Especial) -Universidade Federal de São Carlos, São Carlos, 2019.

SANTOS, V. Análise de indicadores educacionais censitários da política de inclusão escolar: uma proposta metodológica. 2017. 116 f. Dissertação (Mestrado em Educação Especial) - Universidade Federal de São Carlos, São Carlos, 2017.

SCHENINI, Fátima. A construção de práticas educacionais para alunos com altas habilidades/superdotação. s/p. Disponível em: http://portal.mec.gov.br/component/tags/tag/32300. Acesso em: 26 de jun. 2020. SCHWARTZMAN, José Salomão. Síndrome de Rett. Rev. Bras. Psiquiatr. [online]. 2003, v.25, n.2, p.110-113.

SENKEVICS, Adriano Souza; MELLO, Ursula Mattioli. O perfil discente das universidades federais mudou pós-lei de cotas? Cadernos de Pesquisa, São Paulo, v. 49, n. 172, p. 184 208, abr./jun. 2019.

SILVEIRA, T. S. da. Política de inclusão no ensino superior na modalidade EAD nas universidades privadas. 2015. 139f. Dissertação (Mestrado em Educação) - Universidade do Vale do Itajaí, Itajaí, 2015.

URBAN, A. L. P. Um estudo de produções científicas: ingresso e permanência de universitários com deficiência. 2016. 130 f. Dissertação (Mestrado em Educação Escolar) Universidade Estadual Paulista Júlio de Mesquita Filho, Araraquara, 2016.

\section{SOBRE OS AUTORES}

Luiz Renato Martins da Rocha. Doutor em Educação Especial (UFSCar). Universidade Tecnológica Federal do Paraná. Departamento de Educação. Grupo de pesquisa Surdez e Abordagem Bilíngue.

Contribuição de autoria: Escrita - Revisão e Edição Lattes: http://lattes.cnpq.br/4901568089807470.

Cristina Broglia Feitosa de Lacerda. Doutora em Educação (Unicamp). Universidade Federal de São Carlos. Programa de pós-graduação em Educação Especial. Grupo de pesquisa Surdez e Abordagem Bilíngue. Bolsista de Produtividade em Pesquisa 1C. Contribuição de autoria: Escrita - Revisão e Edição Lattes: http://lattes.cnpq.br/9468232016416725.

Elisângela Aparecida da Silva Lizzi. Doutora em saúde na comunidade (USP). Universidade Tecnológica Federal do Paraná. Departamento Acadêmico de Matemática. Contribuição de autoria: Escrita - Revisão e Edição Lattes: http://lattes.cnpq.br/8487600124864253.

\section{Como citar este artigo (ABNT):}

ROCHA, Luiz Renato Martins da; LACERDA, Cristina Broglia Feitosa de; LIZZI, Elisângela Aparecida da Silva. Perfil dos Estudantes público-alvo da Educação Especial na Educação Superior brasileira antes da Lei de Reserva de Vagas. Revista Práxis Educacional, Vitória da Conquista, v. 18, n. 49, 2022.

Notas de Rodapé 


\footnotetext{
' Adotaremos neste artigo o termo Educação Superior, em detrimento a Ensino Superior, haja vista no site do Inep os dados disponíveis se referirem ao Censo da Educação Superior. Na LDB, Lei n 9.394/96, artigo $8^{\circ}$, mencionam-se as instituições de Educação Superior. A Lei no 10.861/2004 institui o Sistema Nacional de Avaliação da Educação Superior - Sinaes (BRASIL, 2004).

ii São estudantes com deficiência, transtornos globais do desenvolvimento e com altas habilidades ou superdotação (BRASIL, 2011). Nos dados disponibilizados pelo Inep (microdados), esse público é pormenorizado na contagem do censo, o que será abordado no decorrer do artigo.

iii Pessoas com deficiências.

iv Formado é o aluno que concluiu a totalidade dos créditos acadêmicos exigidos para titulação no curso durante o ano de referência do Censo. Não é obrigatório que o aluno tenha realizado a colação de grau e/ou participado do Exame Nacional de Desempenho de Estudantes (Enade). (INEP, 2015b, p. 47).

$\checkmark$ Cursando é a situação de vínculo do aluno que não concluiu a totalidade da carga horária exigida para a conclusão do curso, no ano de referência do Censo. No caso das universidades federais, tal situação corresponde ao discente aprovado na disciplina (APV), ou ao discente reprovado por nota ou conceito (REP), ou ao discente reprovado por falta (REF), ou ao discente sem conceito definido (ASC). (INEP, 2015b, p. 47).

vi Curso sequencial é o superior destinado à obtenção ou à atualização de qualificações técnicas, profissionais, acadêmicas ou de desenvolvimento intelectual. É organizado por campo de saber, com diferentes níveis de abrangência, e aberto a candidatos portadores de diplomas de conclusão do nível médio que atendam aos requisitos estabelecidos pelas instituições de ensino (INEP, 2015b, p. 34).

vii Cursos de graduação são cursos superiores que conferem diplomas de bacharel, licenciado ou tecnológo (INEP, 2015b, p. 34).

viii Alunos são desvinculados do curso por motivos de evasão, abandono, desligamento ou transferência para outra IES (INEP, 2015b, p. 47).

ix Aluno falecido durante o ano de realização do Censo, até a data de referência (INEP, 2015, p. 47).

x Aluno com matrícula trancada é aquele que, na data de referência do Censo, está com a matrícula trancada na IES (INEP, 2015b, p. 47).

${ }^{x i}$ Aluno transferido é aquele que passou por mobilidade acadêmica mediante a qual se transferiu para outro curso de graduação da mesma IES (INEP, 2015b, p. 47).

xii (IN_ALUNO_DEF_TGD_SUPER).

xiii Esse dado chamou muito a atenção dos pesquisadores, pois, nessa região, a maioria dos alunos com superdotação/altas habilidades estavam matriculados em uma mesma IES. Foi feito um contato telefônico com o Inep e com a IES e é possível que haja algum problema com o preenchimento do Censo, o que fragiliza afirmações com relação à presença desse público nas quantidades indicadas.

${ }^{\text {xiv }}$ Quando da abertura dos microdados, identificamos que muitos estudantes não estavam marcados como tendo deficiência múltipla, mas, somadas as características, emergiu a existência deles. Por essa razão, resolvemos criar uma nova categoria, para mostrar, por vezes, a fragilidade dos dados.

xv “A Unesco considera a Taxa de Escolarização Bruta na Educação Superior a razão entre a matrícula total na educação superior (ensino de graduação), independentemente da idade dos alunos matriculados, e a população na faixa etária teoricamente adequada ( 5 anos contados a partir do ensino médio; no Brasil, seria de 18 a 22 anos)" (PINTO, 2004, p. 754).
} 